NASA Technical Memorandum 87705

NASA-TM-87705 19860014189

\title{
COMBINED BEARING AND BYPASS LOADING ON A GRAPHITE/EPOXY LAMINATE
}

J. H. CREWS, Jr. and R. A. NAIK

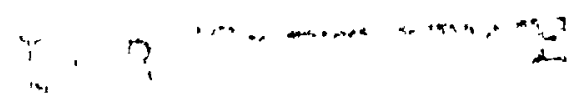

\section{April 1986}

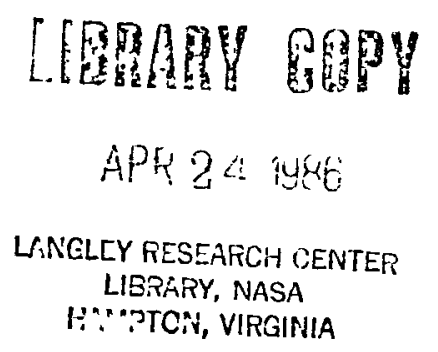


SUMMARY

A combined experimental and analytical study was conducted to determine the behavior of a graphite/epoxy laminate subjected to combined bearıng and bypass loading. Single-fastener quasi-isotropic specimens were loaded at varıous bearıng-bypass ratios until damage was produced at the fastener hole. Damage-onset strengths and damage modes were then analyzed using local hole-boundary stresses calculated by a finite-element analysis. The tension data showed the expected linear interaction for combined bearing and bypass loading with damage developing in the net-section tension mode. However, the compression bearing-bypass strengths showed an unexpected interaction involving the bearing mode. Compressive bypass loads reduced the bearing strength by decreasing the bolt-hole contact arc and thus increasing the severity of the bearing loads. The bearing stresses at the hole boundary were not accurately estimated by superposition of the stress components for separate bearing and bypass loading. However, superposition produced reasonably accurate estimates for tangential stresses especially near the specimen net-section. 


\section{INTRODUCTION}

In the past, design procedures for mechanically-fastened joints in composites have usually been very conservative. In such cases, fallures were usually avolded by heavily reinforcing the laminates in the vicinity of the joints. Needed improvements in joint efflciency require data bases for laminates tested under conditions typical of structural joints. Within a multi-fastener structural joint, fastener holes may be subjected to the combined effects of bearing loads and loads that bypass the hole, as lilustrated in Fig. 1. The ratio of bearing load to bypass load depends on the joint stiffness and configuration. As the joint is loaded, this bearing-bypass ratio remains nearly constant until joint damage develops. Although the combined effects of bearing and bypass loads can be simulated by testing single-fastener specimens, such tests are difficult. The varlous approaches used for bearing-bypass testing have involved complex apparatus to simultaneously apply the bearing and bypass loads. As a result, very little bearing-bypass data have been reported. Virtually nothing has been reported for bearing-bypass loading in compression. The first objective of this paper is to introduce a relatively simple approach for combined bearing-bypass testing that works equally well in tension and compression. This approach was demonstrated by testing a graphite/epoxy laminate. The second objective is to analyze the effects of combined bearing and bypass loading by examining the computed local stresses associated with laminate damage at fastener 
holes. This paper also evaluates the use of superposition to calculate local stresses for combined bearing and bypass loading.

The test approach presented in this paper employs two hydraulic servo-control systems synchronized to apply proportional bearing and bypass loads to a laminate specimen with a central hole. The laminate tested was T300/5208 graphite/epoxy with a 16-ply quasiisotropic layup. The bearing loads were applied through a $6.35 \mathrm{~mm}$ steel bolt with a clearance fit. To simplify the present study, each test was stopped when its load displacement record began to indlcate specimen damage. Ref. 1 showed that such damage onset could be accurately analyzed using the elastic stresses at the hole boundary. The test results were plotted as a bearing-bypass strength diagram for damage onset. The damage modes were determined by radiographing each specimen after testing.

The hole-boundary stresses corresponding to the measured damage onset strengths were calculated using a finite-element procedure that accounted for bolt clearance. This stress analysis provided the basis for discussing the various bolt-hole contact conditions that developed during bearing-bypass testing. These stresses allowed the local interactions between the two types of loading to be evaluated for both tension and compression. Also the hole-boundary stress distributions were compared for separate bearing and bypass loading as well as combined loading. 


\section{NOMENCLATURE}

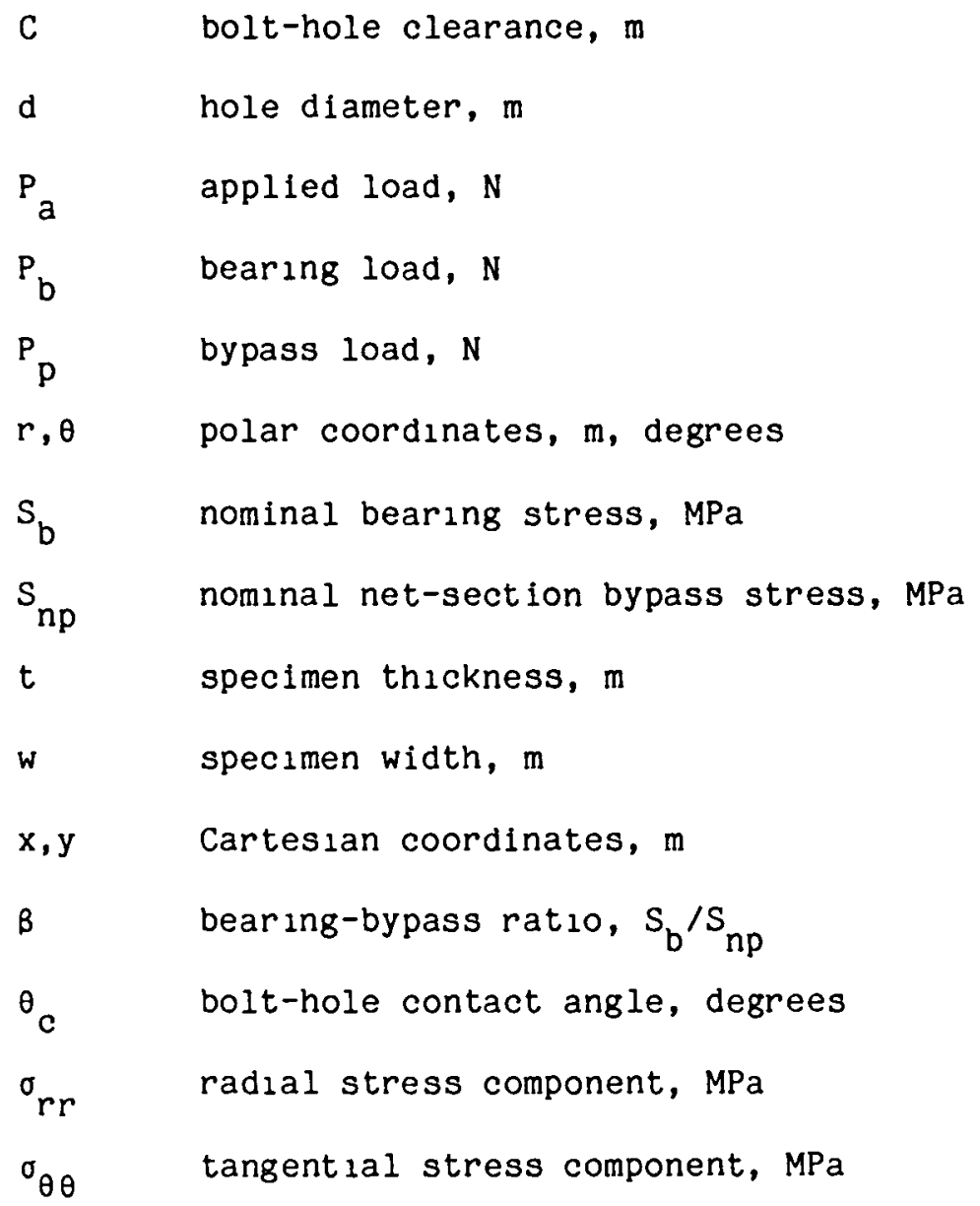

Three approaches to bearing-bypass testing have been used in the past with simple specimens. The first approach uses levers and linkages to divide the applied load into two proportional parts ${ }^{2}$. One part acts on the end of the specimen and the other is reacted as a bearing load at the specimen hole. The bolt hole is thereby subjected to proportional bearing and bypass loading. The lever fulcrum points can be changed to produce different ratios of bearing to bypass loading. This lever-linkage approach works well for 
tension bearing-bypass loading but 1 s difflcult to apply in compression. The second approach to bearing-bypass testing uses a "scissor" mechanism to apply a bearing load between two holes in the test specimen ${ }^{3}$. This bearing load is held constant while the bypass load is increased until the specimen falls. Although this approach does produce bearing-bypass loading in tension or compression, it does not maintain the desired constant ratio of bearing to bypass loads. Furthermore, this approach could alter the sequence of local damage development. The third approach uses two servo-control systems; one controls the bearing load while the other controls the bypass load ${ }^{4}$. The bypass load is applied to the end of the specimen in the conventional manner; however, the bearing load is applied through linkages with two hydraulic cylinders connected to the ends of a bearing bar which is bolted to the specimen. Constant bearing bypass ratios could be maintained by synchronizing the two control systems. Although this concept works in tension and compression, the test apparatus is rather complex and quite different apparatus arrangements are needed for the two types of loading.

Although developed independently, the new test system has some similarity to that in Ref. 4. As in Ref. 4, the new system has two servo-control systems. However, the present dual-control arrangement uses an apparatus that is much simpler than that in Ref. 4. Fig. 2(a) shows the test specimen and Fig. 3 shows a block dlagram of the test system. The center of the specimen is clamped between two "bearing-reaction" plates that are attached to the load frame. The two ends of the specimen are then loaded independently by the two servo-control systems (called upper and lower in Fig. 3). Any 
difference between these two loads produces a bearing load at the central bolt hole. This bearing load is measured by the two load cells under the bearing-reaction plates. The end loads are synchronized by a common input signal. As a result, a constant bearing-bypass ratio is maintained throughout edch test.

A photograph of the apparatus is shown by Fig. 4. Only a small portion of the specimen edge is visible. This photograph shows the friction grips that load each end of the specimen and the head of the $6.35 \mathrm{~mm}$ steel bolt that attaches the specimen to the bearingreaction plates. Notice that the bearing-reaction plates are bolted to the bearing load cells. This allows elther tension or compression bearing loads to be reacted by these load cells. During compression loading, the bearing-reaction plates prevent specimen buckling.

The specimen deformation was measured throughout each test using displacement transducers. These transducers (DCDT) were mounted symmetrically on the front and back of the bearing reaction plates. (These plates were made with nonmagnetic 347 stainless steel so they would not affect the transducer performance.) The transducer rods were cemented to small bars that were attached to the specimen slightly above the gripline as shown in Fig. 4. This arrangement provided a measurement of the relative displacement between the bearing-reaction plates and the specimen. These measurements were used to determine the damage onset, as explained in the next section. Although not visible in Fig. 4, hardened steel bushings were used between the bolt and the bearing-reaction plates. These bushings had a $12.7 \mathrm{~mm}$ outside diameter that was machined for a sliding fit, thus allowing the bolt clampup force to be transmitted 
to the local region around the bearing-loaded hole. This arrangement was equivalent to having a clampup washer directly against each face of the laminate, as used in Refs. 1 and 5.

The test speclmens were fabricated from 16-ply quasiisotropic graphite/epoxy laminates (T300/5208) with a $[0 / 45 / 90 /-45]_{2 \mathrm{~s}}$ layup. The specimen configuration is shown in Fig. 2(a). The bolt holes were machined using an ultrasonic diamond-core drill. A hole diameter of $6.396 \mathrm{~mm}$ was used for a clearance of $0.076 \mathrm{~mm}$ with the $6.320 \mathrm{~mm}$ steel bolts. This clearance was 1.2 percent of the hole diameter and is typical of aircraft joints. The bolts were finger tightened (about $0.2 \mathrm{~N} . \mathrm{m}$ torque) to produce a very small clampup force against the specimen.

The loading notation is shown in Fig. 2(b). The test results are presented in terms of nominal stress rather than load. The nominal bearing stress $S_{b}$ and nominal net-section bypass stress $S_{n p}$ were calculated from the following equations:

$$
S_{b}=P_{b} / t d
$$

and

$$
S_{n p}=P_{p} / t(w-d)
$$

The bearing-bypass ratio $\beta$ was defined as

$$
B=S_{b} / S_{n p}
$$


In each test, the nominal bearing and bypass stresses were plotted against specimen displacement. The tests were conducted at the rather slow rate of $3.75 \mathrm{~N} / \mathrm{s}$ for the applied load $\mathrm{P}_{\mathrm{a}}$. Typical load-displacement curves are shown in Fig. 5 for a bearing-bypass ratio of -1 . The two curves have a small initial nonlinearity (due to varying contact arc) but gradually develop a nearly linear response. At higher load levels, the curves gradually develop a second nonlinearlty. This second nonlinearlty indicates damage at the bolt hole, as discussed in Ref. 1 . An offset of $0.001 \mathrm{~d}$ was selected to define the damage onset level, as shown in Fig. 5. Soon after the damage-onset level was reached, the specimens were unloaded. They were then treated with an X-ray opaque dye-penetrant and radiographed to determine the damage location along the hole boundary. The damage-onset mode was deduced from the damage location as discussed in the next section.

\section{TEST RESULTS}

Results from the bearing-bypass tests are presented in Table 1 and Fig. 6. Symbols in Fig. 6 represent measured $S_{b}$ and $S_{n p}$ values corresponding to damage onset. Each symbol represents an average of three tests. The right side of Fig. 6 shows tension results for four $B$ values $(0,1,3$, and $\infty)$. The left side shows the corresponding compression results. Fig. 6 also indicates the observed failure mode for each test condition. The NT beside some symbols indicates net-section tension damage. For these cases, radiographs showed damage near $\theta=90^{\circ}$ on the hole boundary, as 
shown in Fig. $7(a)$. Continued loading would probably have failed the specimens through the net-section. The TRB in Fig. 6 indicates bearing damage onset for tension-reacted bearing loads. This damage developed at the upper edge of the hole, as shown in Fig. 7(b).

The tension cases with NT damage $(B=0,1$ and 3$)$ can be represented by a straight line and thus show the linear "interaction" discussed by Hart-Smith in Ref. 6. This linearity suggests that the local stresses, responsible for damage onset, can be assumed to consist of a component due to bearing and a second superimposed component due to bypass loading. This assumption wlll be Investigated later in this paper. The "bearing cutof $f^{\text {" reported by }}$ Hart-Smith ${ }^{6}$ was represented by a horizontal line through the $\beta=\infty$ data point. These two straight lines through the data represent the damage onset strength for combinations of bearing-bypass loading in tension.

The left side of Fig. 6 presents data for compression loading. The CRB indicates bearing damage for compression-reacted bearing loads. As shown in Fig. $7(\mathrm{c})$, CRB damage developed at the lower edge of the hole. Damage for $\beta=-\infty$ occurred at a slightly higher strength than for the tension-reacted bearing $\beta=\infty$. This small difference may be due to strength variability and is not believed to be significant. The bearing-cutoff response, assumed for tension, does not apply for compression. When compression bypass loading was combined with compression-reacted bearing $(\beta=-3)$, CRB damage developed at a lower load level than for the $\beta=-\infty$ case. This bearing-failure interaction was not expected. Even for $B=-1$, CRB damage was observed, although net-section compression (NC) damage 
was also present. For the remote compression case $(B=0)$, NC damage onset occurred at $-445 \mathrm{MPa}$, compared to $320 \mathrm{MPa}$ for the corresponding $B=0$ tension case. The basic laminate strength is only about 10 percent higher in compression than in tension, therefore, the higher NC damage-onset strength is believed to be attributable to the "dual" bolt-hole contact that allows load transfer across the hole. This load transfer decreases the netsection stress concentration and thereby increases the damage-onset strength for the NC mode. The dashed curve in Fig. 6 indicates the threshold for dual contact and will be discussed in the next section. The radiographs in Fig. 7 also show a difference between the $\mathrm{NT}$ and NC damage cases. Gray shadows, which indicate delamination, are evident in the NT radiographs but not in the NC radiographs.

\section{FAILURE ANALYSIS}

First, this section describes the finite element procedures used to calculate the hole boundary stresses. This section presents local stresses for separate bearing and bypass loads and then presents stresses for combined bearing-bypass loading corresponding to the measured damage-onset strengths. As previously mentioned, these local stresses are used to analyze the measured strength levels and fallure modes. Finally, these local stresses are used to evaluate the assumption that superposition of local stresses for separate bearing and bypass loadings can be used to estimate the local stresses for combined bearıng-bypass loading. 


\section{Finite Element Procedures}

The finlte element procedures used in this study were presented and evaluated in Ref. 7. Because a bolt clearance was used in the present study, the contact arc at the bolt-hole interface varied with applied load. This nonlinear problem was reduced to a linear problem by using an inverse technique. For the simple bearing loading used in Ref. 7 , a contact angle was assumed and the corresponding bearing load was calculated. This procedure was repeated for a range of contact arcs to establish a relationship between contact angle and bearing load. In the present study, this procedure was extended to include combined bearing and bypass loading by using only constant values of the bearing-bypass ratio. For each bearing-bypass ratio $B$, the combined bearing and bypass loading was expressed in terms of bearing stress $S_{b}$ and $B$. Thus, given a $B$, the procedure was identical to that used in Ref. 7 . Again this procedure was repeated to establish a relationship between contact angle and bearing-bypass loading for each $\beta$ value used in the test program.

These calculations were performed using the NASTRAN finite element code. This code is well sulted for the inverse technique because the contact arc can be represented using displacement constraints along a portion of the hole boundary. Displaced nodes on the hole boundary were constrained to lie on a circular arc corresponding to the bolt surface. This represented a rigid bolt having a frictionless interface with the hole. A very fine twodimensional mesh was used to model the test specimen. Along the hole 
boundary, elements subtended less than $1^{\circ}$ of arc. As a result, the contact arc could be modelled very accurately.

\section{Separate Bearıng and Bypass Loadıng}

Fig. 8 shows $\sigma_{\theta \theta}$ and $\sigma_{r r}$ stress distributions calculated for the hole boundary for three different cases. The dash-dot curve shows a familiar distribution of $\sigma_{\theta \theta}$ for the case of remote tension loading $(\beta=0)$ using the measured strength of $S_{n p}=320 \mathrm{MPa}$. As previously mentioned, the damage for this test case was found to develop in the NT mode and, therefore, was governed by the $\sigma_{\theta \theta}$ stress near $\theta=90^{\circ}$. The dash-dot curve has a peak value of about $830 \mathrm{MPa}$ near $\theta=90^{\circ}$. This computed peak value grossly exceeds the unnotched laminate tensile strength of $414 \mathrm{MPa}^{8}$. Part of this discrepancy can be explained by the fact that the peak local stress acts over a very small volume of material subjected to a high stress gradient. The peak local strength should be higher than the unnotched tensile strength obtained using a relatively large tensile coupon under uniform stress. Also the NT damage onset reduced the stress concentration for the region of peak $\sigma_{\theta \theta}$ stress. Because the stress analysis did not account for this reduction, the computed peak $\sigma_{\theta \theta}$ was somewhat overpredicted. However, Ref. 1 showed that this computed $\sigma_{\theta \theta}$ peak corresponding to NT damage should agreee with similar peak values calculated for the other cases with NT damage. The peak value of $830 \mathrm{MPa}$ from Fig. 8 will therefore be used in subsequent analyses to indicate critical conditions for the onset of NT damage. 
The dashed curves in Fig. 8 represents tension-reacted bearing loading $(\beta=\infty)$ with a zero clearance (snug $f_{1}$ ) between the bolt and hole. This is a special reference case that has been widely analyzed because it is a linear problem (the contact angle does not vary with loading). The dashed ${ }^{\circ} \mathrm{rr}$ curve indlcates an $82.5^{\circ}$ contact angle for this case, which agrees quite well with the $83^{\circ}$ value reported in Refs. 9 and 10. Notice that the peak in the dashed $\sigma_{\theta \theta}$ curve occurs slightly beyond the end of the contact arc established by the $\sigma_{r r}$ contact stress. The magnitude of this $\sigma_{\theta \theta}$ peak agrees with results in Ref. 11.

The two solid curves in Fig. 8 represent the tension-reacted bearing test case $(\beta=\infty)$. The loading for this case corresponded to $S_{b}=518 \mathrm{MPa}$, the observed bearing damage-onset strength in tension. A bolt clearance of $0.076 \mathrm{~mm}$ was also used to correspond to the test program value. The solid $\sigma_{\mathrm{rr}}$ curve shows that contact developed over about $60^{\circ}$ compared to more than $80^{\circ}$ for the snug-f 1 t reference case with the same loading level. This smaller contact arc resulted in a higher peak value in the $\sigma_{r r}$ curve. This peak value of about $-730 \mathrm{MPa}$ exceeded the unnotched laminate compressive strength of 455 $\mathrm{MPa}^{8}$, as expected. This peak value of $-730 \mathrm{MPa}$ will be used in the remainder of this paper to indicate critical hole-boundary conditions for bearing damage onset.

\section{Combined Bearing and Bypass Loading}

Tension: The two test cases from Fig. $8(\beta=0$ and $\infty)$ are replotted in Fig. 9 for comparison with the other two tension test 
cases $(\beta=1$ and 3$)$. All four sets of curves in Fig. 9 correspond to the measured load levels for damage onset. For $\beta=0,1$ and 3 , the $\sigma_{\theta \theta}$ curves have peak values near $\theta=90^{\circ}$, all within about 7 percent of $830 \mathrm{MPa}$, the critical value for NT damage. This is consistent with the earlier observation that all three of these cases developed damage in the NT mode. Conversely, for the bearing critical $B=\infty$ case, note that the $\sigma_{\theta \theta}$ peak of about $600 \mathrm{MPa}$ is well below the critical $830 \mathrm{MPa}$ level for NT damage. The $\sigma_{\mathrm{rr}}$ peaks for $B=1$ and 3 are well below the critical $-730 \mathrm{MPa}$ level for bearing damage. Compression: Fig. 10 compares the hole-boundary stress distributions for the four compression test cases $(\beta=0,-1,-3$, and $-\infty)$. As expected, the $\sigma_{\theta \theta}$ and $\sigma_{r r}$ curves for $\beta=-\infty$ are quite similar to those for $\beta=\infty$. The $\sigma_{\theta \theta}$ peak of about $500 \mathrm{MPa}$ is slightly lower than the $600 \mathrm{MPa}$ peak for $\beta=\infty$ and much lower than the critical $830 \mathrm{MPa}$ level for NT damage. The $\sigma_{\mathrm{rr}}$ peak of about $-810 \mathrm{MPa}$ for $\mathrm{CRB}$ damage is slightly larger than the $-730 \mathrm{MPa}$ level determined from the TRB $B=\infty$ case. This higher or peak for compression loading should have caused a lower strength, compared to the corresponding tension case. However, just the opposite was shown earlier in Fig. 6. This discrepancy is rather small and may be due to material strength variability.

Recall that the CRB damage-onset strength decreased as the bypass load was increased, see the $\beta=-\infty,-3$, and -1 cases in Fig. 6. This interaction was unexpected because the damage developed in the CRB mode and the compressive bypass loads were not believed to contribute to the $\sigma_{r r}$ stresses that cause CRB damage. The interaction for CRB cases can be explained using Fig. 10. The peak 
$\sigma_{r r}$ stresses for $\beta=-\infty,-3$, and -1 in F1g. 10 are nearly equal and are all slightly higher than $-730 \mathrm{MPa}$, the critical level for bearing damage. Fig. 10 also shows, that for these three cases, the lower the bearing load the smaller the contact arc. The smaller contact arcs compensate for the smaller bearing loads. The compressive bypass loads decrease contact arc length and allow the bearing loads to be more damaging. Therefore, the effect of the compressive bypass loads on the contact arc is responsible for the observed decrease in strength for CRB damage-onset. This discussion of contact angle suggests that a similar interaction probably exists in tension. The horizontal bearing-cutoff line probably underestimates the actual strength for small $S_{n p}$ levels.

As previously mentioned, the compressive $\beta=0$ case in F1g. 10 involves dual contact. For this case, the hole deforms enough to contact the bolt, starting at $B=0$ and $180^{\circ}$. The dashed curve in Fig. 6 represents the calculated threshold for dual contact with a $0.076 \mathrm{~mm}$ initial bolt clearance. This dashed curve shows that contact started near $S_{n p}=-220 \mathrm{MPa}$ for $\beta=0$. The $\beta=0$ curve in Fig. 10, for $S_{n p}=-445 \mathrm{MPa}$, shows that the contact extended by about $\pm 20^{\circ}$ around $\theta=0$ and $180^{\circ}$. The ${ }^{\sigma} \theta \theta$ curve for $\beta=0$ has a compressive peak of about $-970 \mathrm{MPa}$. This peak caused the net-section compression (NC) damage observed for this case. As discussed earlier, the dual contact in this case elevated the specimen strength compared to cases with clearances sufficient to prevent such contact. Conversely, the present strength is less than that expected for the snug-fit case. 
The results in this section demonstrate that local holeboundary stresses can be compared with critical stress levels to predict damage modes and damage-onset strengths.

\author{
Local Stress Superposition
}

The stress distributions in the previous section were calculated with a separate finite-element analysis for each bearingbypass loading in the test program. These stress analyses would have been simplified if the stresses due to the separate bearing and bypass loading could have been superimposed to get the results for combined bearing-bypass loading, as suggested in Ref. 12. This section investigates the accuracy of such a superposition procedure.

Obviously such a superposition must represent the contact angles properly to be accurate. Fig. 11 shows contact angles plotted against bearing stress for varıous bearing-bypass ratios. The open symbols represent a range of cases for tension- and compressionreacted bearing. The solid curves were drawn through these symbols to determine the nonlinear relationship between the contact angle and the bearing stress. The solid symbols represent test cases and, therefore, correspond to the measured damage-onset strengths and the calculated contact angles discussed in earlier figures. When superposition is used to analyze a specimen with bearing-bypass loading, the contact angle would be determined solely by the bearing component of the solution. The contact angle would, therefore, be given by one of the solid curves in Fig. 11. These solid curves provide rather poor estimates of contact angle for most of the test 
cases, underestimating for tension and overestimating for compression. The contact angle estimates are especially bad for the $\beta=1$ and -1 cases. For this reason, these two cases were selected for further analysis of the superposition technique.

Computed results for the $\beta=1$ test case are shown in Fig. 12. The test value of $S_{b}=250 \mathrm{MPa}$ was used to calculate the component of local stresses caused by bearing and $S_{n p}=250 \mathrm{MPa}$ was used to calculate the bypass component. These stress distributions were added to get the dashed curve shown in the figure. For comparison, the solid curve representing the combined bearing and bypass loading is replotted from Fig. 9. As expected, the low estimate for the contact angle produced a high estimate for the ${ }^{\sigma} \mathrm{rr}$ peak. However, the $\sigma_{\theta \theta}$ distribution was surprisingly accurate, especially in the net-section $\left(\theta=90^{\circ}\right.$ ) region. A similar comparison for $\beta=-1$ is shown in Fig. 13. Again, the $\sigma_{r r}$ distribution is poorly estimated by superposition but the $\sigma_{\theta \theta}$ distribution is remarkably accurate near the specimen net-section. Superposition was also used to calculate local stresses for the $\beta=3$ and -3 test cases. The trends were similar to those shown in Figs. 12 and 13.

These stress distribution comparisons suggest that superposition can provide useful estimates of the $\sigma_{\theta \theta}$ stresses associated with net-section damage in tension as well as compression. However, contact angle errors produce significant errors in the ${ }^{\sigma} \mathrm{rr}$ distributions. As a result, superpositon should not be used to predict bearing strength. 


\section{CONCLUDING REMARKS}

A combined experimental and analytical study was conducted to determine the behavior of a graphite/epoxy laminate subjected to combined bearing-bypass loading. Single-fastener, quasi-isotropic specimens were loaded at varıous bearing-bypass ratios until damage was produced at the fastener hole. Damage-onset strengths and damage modes were then analyzed using hole-boundary stresses calculated by a finite-element analysis.

A dual-control test system, described in this paper, was used to sucessfully measure damage-onset strengths for a wide range of bearing-bypass load ratios in both tension and compression. The tension data showed the expected linear interaction for combined bearing-bypass loading with damage developing in the net-section tension mode. However, the compression bearing-bypass strengths showed an unexpected interaction of the bearing and bypass loads. Compressive bypass loads reduced the bearing strength. This effect was analyzed and explained using the hole-boundary stresses. The compressive bypass loads were shown to decrease the bolt-hole contact arc and, thus, increase the severity of the bearing loads.

The bearing stresses at the hole boundary were not accurately estimated by the superposition of the stress components for separate bearing and bypass loadings. The errors were traced to discrepancies in the calculated bolt-hole contact arcs. However, the superposition approach produced reasonably accurate estimates for the tangential stresses, especially near the specimen net-section. 
REFERENCES

1. Crews, J. H., Jr. and Naik, R. A.: "Failure Analysis of a Graphite/Epoxy Laminate Subjected to Bolt Bearing Loads," NASA TM 86297, Aug. 1984.

2. Ramkumar, R. L.: "Bolted Joint Design, Test Methods and Design Analysis for Fibrous Composites", ASTM STP 734, C. C. Chamis Ed. American Society for Testing and Materials, 1981, pp. 376-395.

3. Garbo, S. P.: "Effects of Bearing/Bypass Load Interaction on Laminate Strength," AFWAL-TR-82-3114, Sept. 1981.

4. Concannon, G.: "Design Verification Testing of the $x-29$ Graphite/Epoxy Wing Covers", Proceedings of the Fall Meeting, Soclety of Experimental Stress Analysis, Salt Lake City, Utah, 1983, pp. 96-102.

5. Crews, J. H., Jr.: "Bolt-Bearıng Fatigue of a Graphite/Epoxy Laminate. Joining of Composite Materials," ASTM STP 749 , K. T. Kedward, Ed., American Society for Testing and Materials, 1981, pp. 131-144.

6. Hart-Smith, L. J.: "Bolted Joints in Graphite/Epoxy Composites," NASA CR-144899, National Aeronautics and Space Administration, Jan. 1977.

7. Naik, R. A. and Crews, J. H., Jr.: "Stress Analysis Method for a Clearance Fit Bolt under Bearing Loads," Presented at AIAA/ASME/ASCE/AHS 26th Structures, Structural Dynamics and Materials Conference, Apr. 15-17, Orlando, FL, 1984 (AIAA Paper 85-0746).

8. DOD/NASA Advanced Composites Design Guide, Vol. IV-A: Materials, First Edition, Contract No. F33615-78-C-3203, A Ir Force Wright Aeronautical Laboratories, July 1983. (Avallable as NASA CR173407 and from DTIC as AD B080 184L.)

9 DeJong, Theo: "Stresses Around Pin-Loaded Holes in Elastically Orthotropic or Isotropic Plates", J. Composite Materials, Vol. 11, July 1977, pp. 313-331.

10. Eshwar, V. A.; Dattaguru, B.; and Rao, A. K.: "Partial Contact and Friction in Pin Joints", Rep. No. ARDB-STR-5010, Dep. Aeronaut. Eng., Indian Inst. Sci., Dec. 1977.

11. Crews, J. H.,Jr., Hong, C. S. and Raju, I. S., "Stress-Concentration Factors for Finite Orthotropic Laminates with a Pin-Loaded Hole", NASA TP-1862, May 1981. 
12. Crews, J. H., Jr.: "A Survey of Strength Analysis Methods for Laminates with Holes", Journal of the Aeronautical Society of Indra, Vol. 36, No. 4, Nov. 1984, pp. 287-303. 
Table 1. Damage-onset data.

\begin{tabular}{|l|c|c|c|c|}
\hline \multirow{4}{*}{ Tension } & $\begin{array}{l}\text { Bearing- } \\
\text { bypass } \\
\text { ratio }\end{array}$ & \multicolumn{2}{|c|}{ Damage-onset strength } & $\begin{array}{l}\text { Damage } \\
\text { onset } \\
\text { mode }\end{array}$ \\
\cline { 3 - 5 } & 0 & $\mathrm{~S}_{\mathrm{b}}, \mathrm{MPa}$ & $\mathrm{S}_{\mathrm{np}}, \mathrm{MPa}$ & $\mathrm{NT}$ \\
& 1 & 250 & 320 & $\mathrm{NT}$ \\
& 3 & 471 & 157 & $\mathrm{NT}$ \\
& $\infty$ & 518 & 0 & $\mathrm{TRB}$ \\
\hline \multirow{5}{*}{ Compression } & 0 & 0 & -445 & $\mathrm{NC}$ \\
& -1 & 324 & -324 & CRB/NC \\
& -3 & 471 & -157 & CRB \\
& $-\infty$ & 540 & 0 & CRB \\
\hline
\end{tabular}

a NT - net-section, TRB - tension-reacted bearing, CRB compression-reacted bearing, NC - net-section compression. 


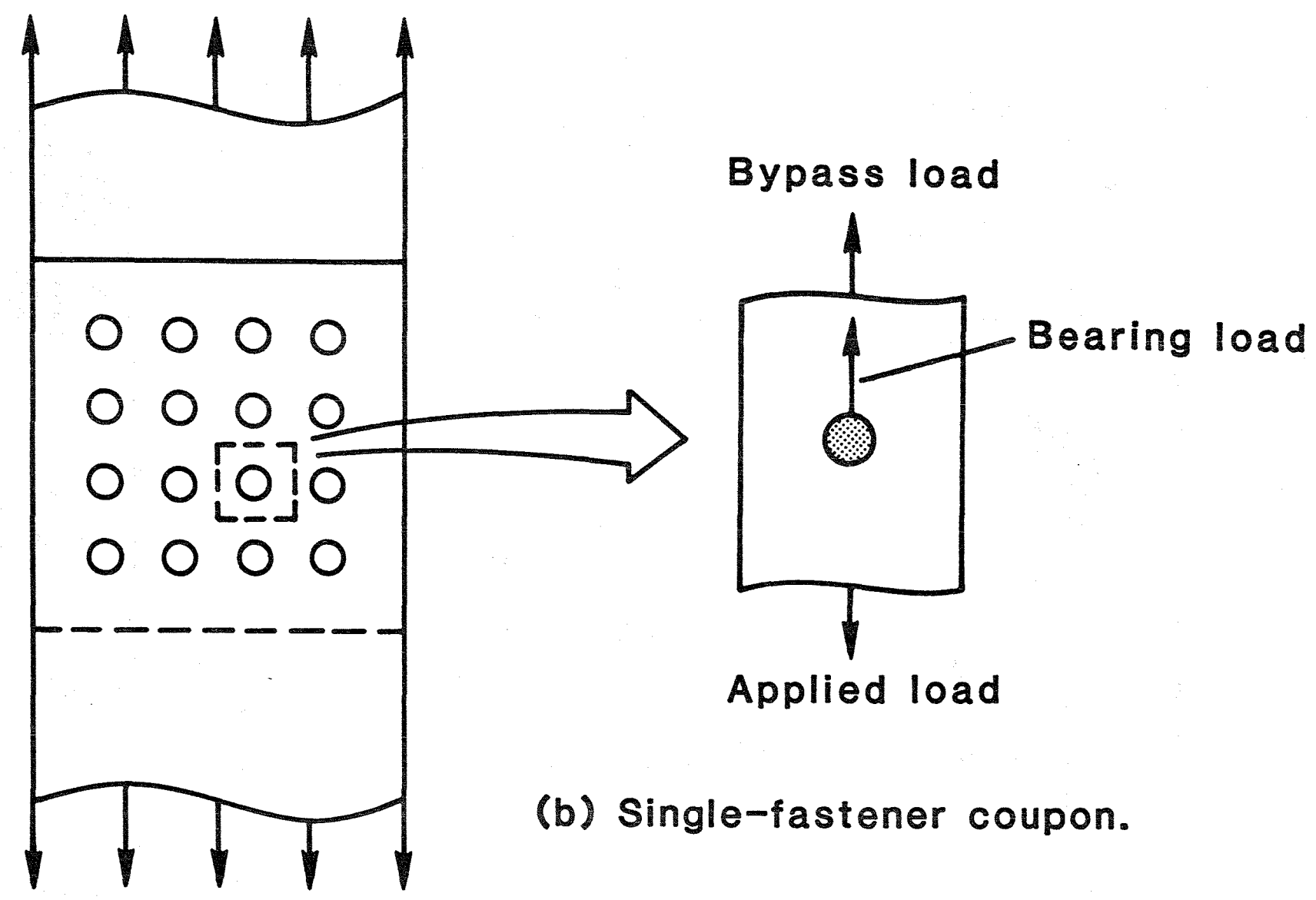

(a) Multi-fastener joint.

Figure 1. Bearing-bypass loading within a multi-fastener joint. 


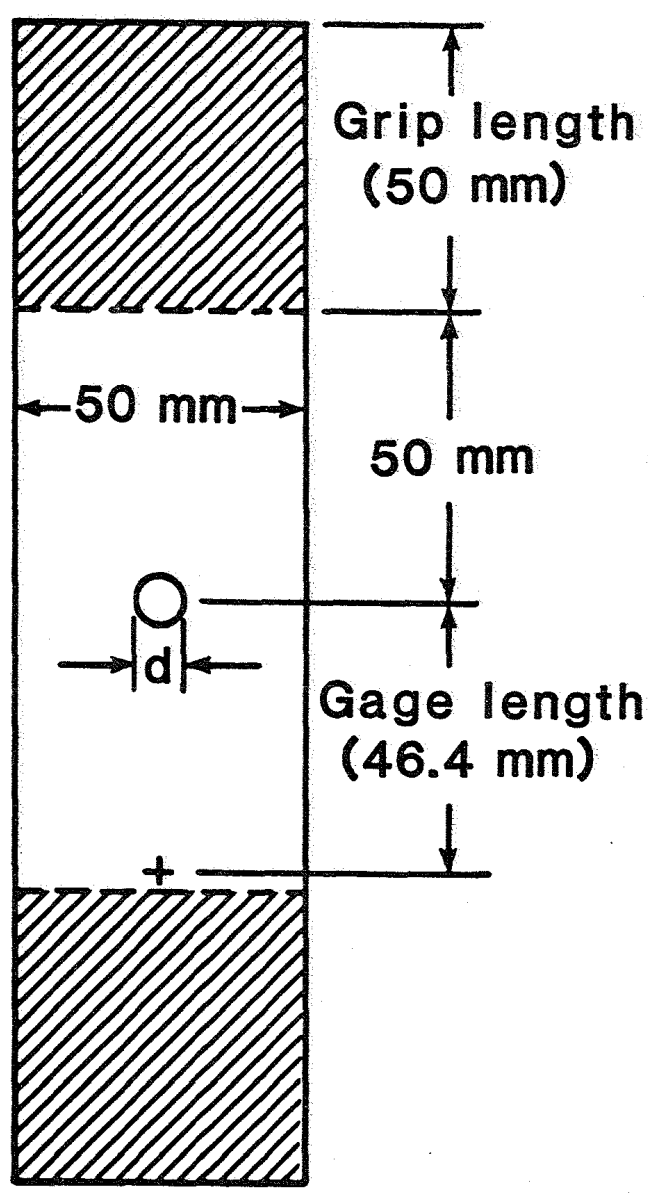

(a) Test specimen

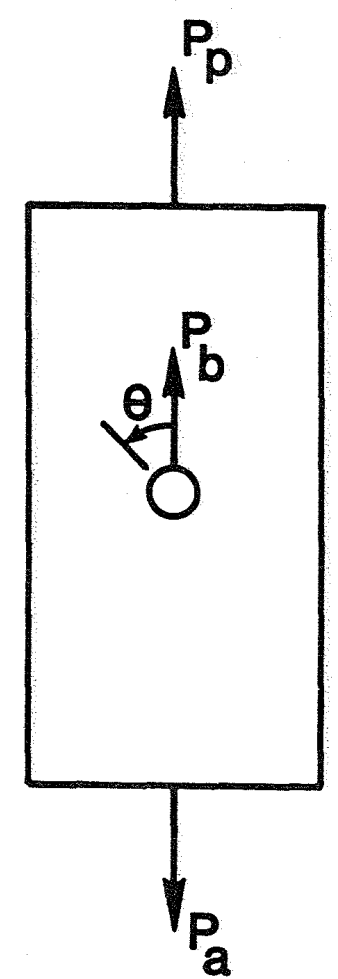

Tension

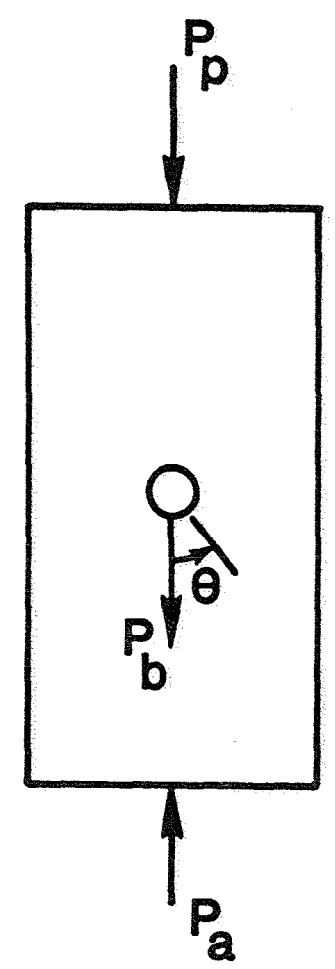

Compression

(b) Bearing-bypass loading 


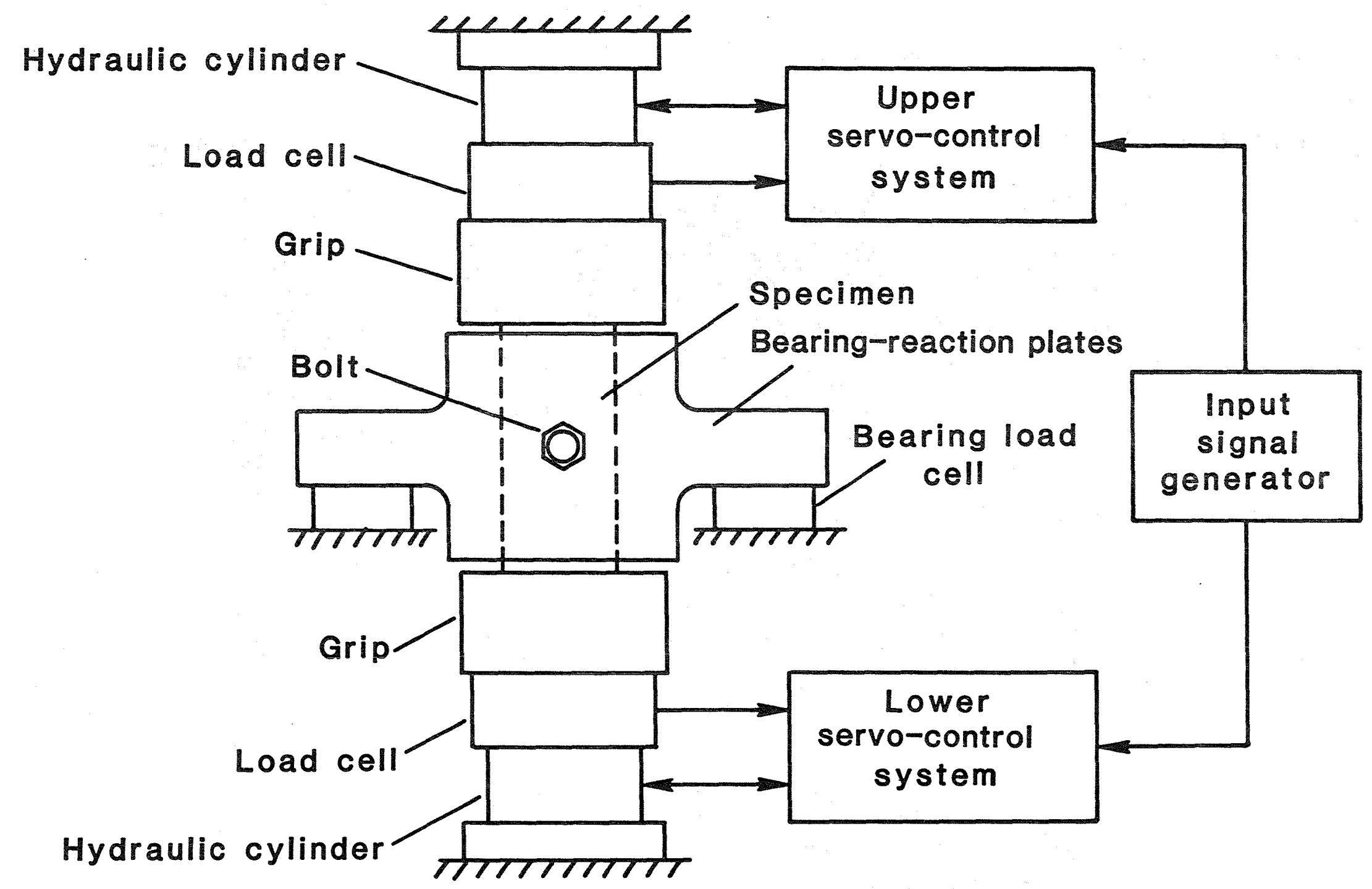

Figure 3. Block diagram of the combined bearing-bypass test system. 




Figure 4. Photograph of bearing-bypass test apparatus. 


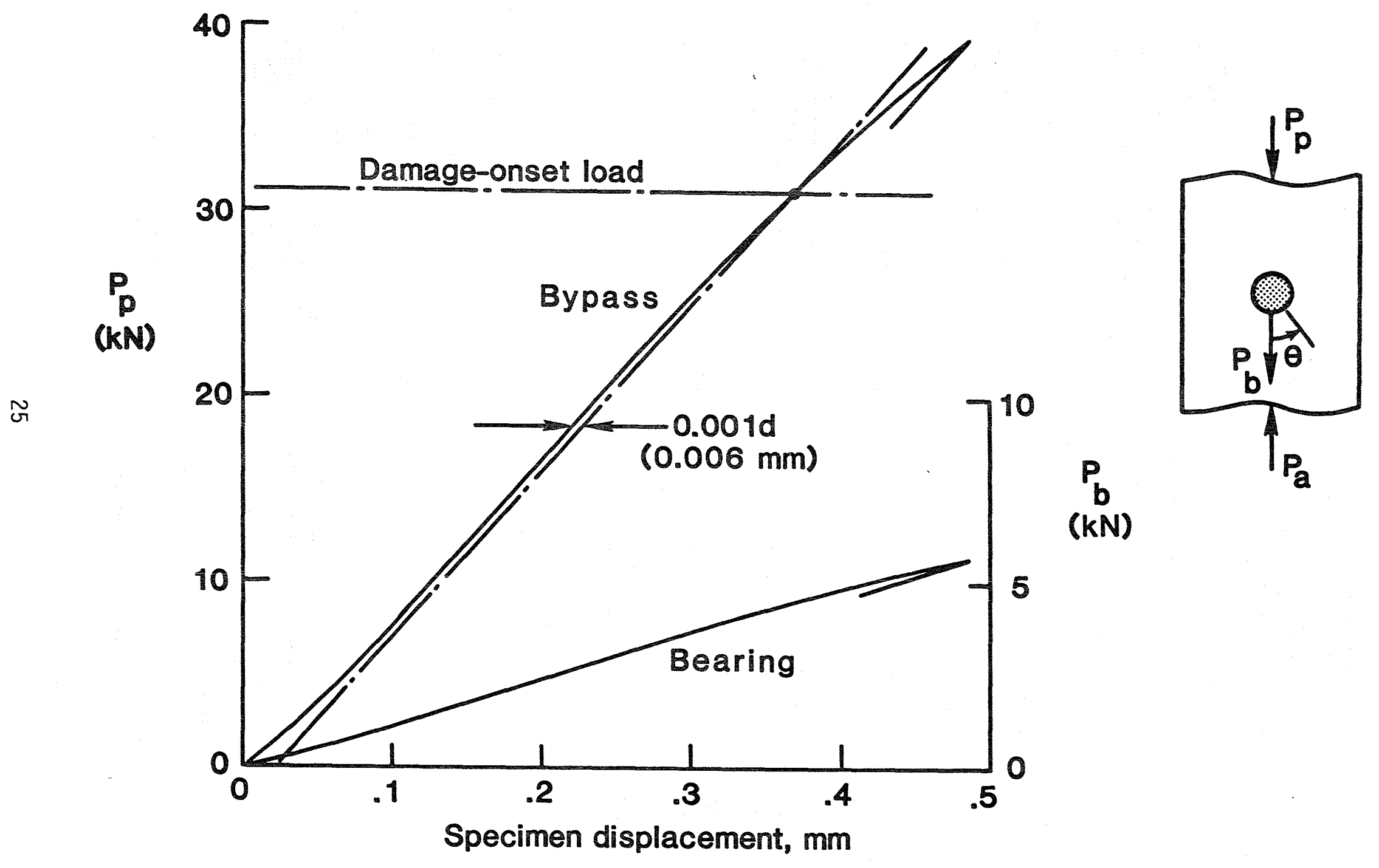

Figure 5. Typical load-displacement curves, $\beta=-1$. 


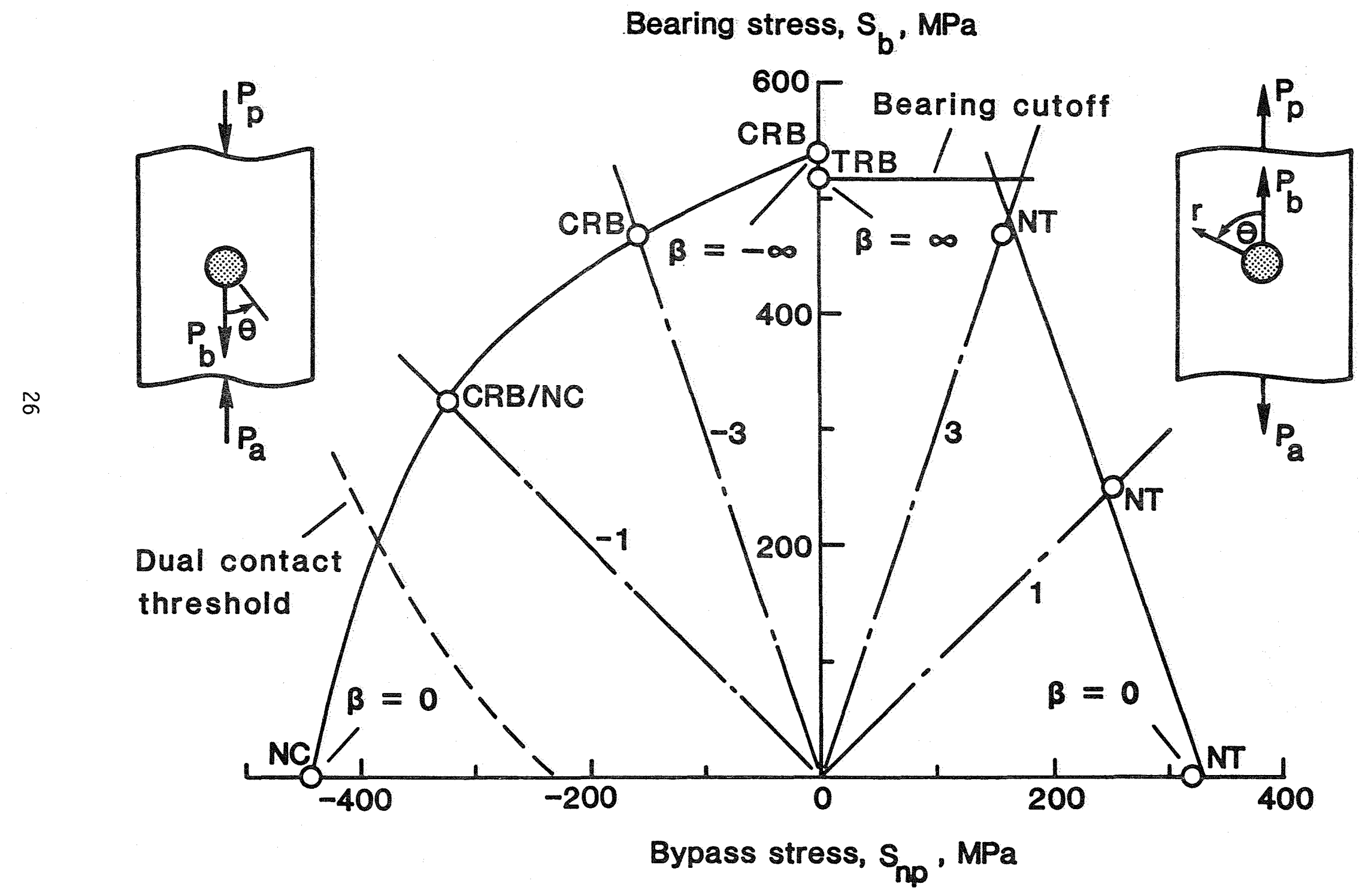

Figure 6. Bearing-bypass diagram for damage onset strength. 


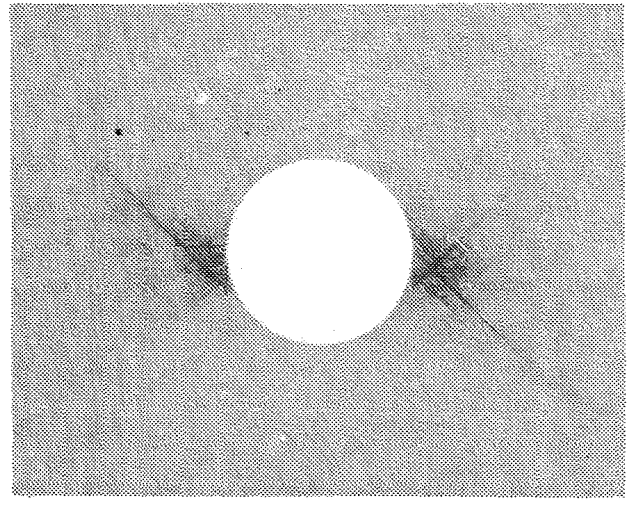

(a) Net-section tension (NT)

$\stackrel{2}{2}$



(c) Compression-reacted bearing (CRB)

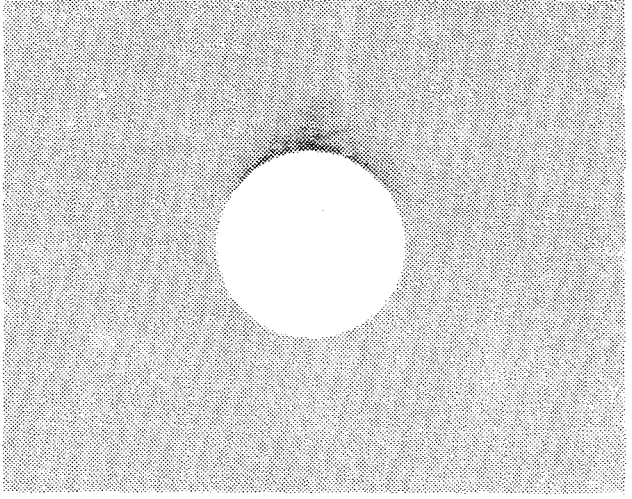

(b) Tension-reacted bearing (TRB)

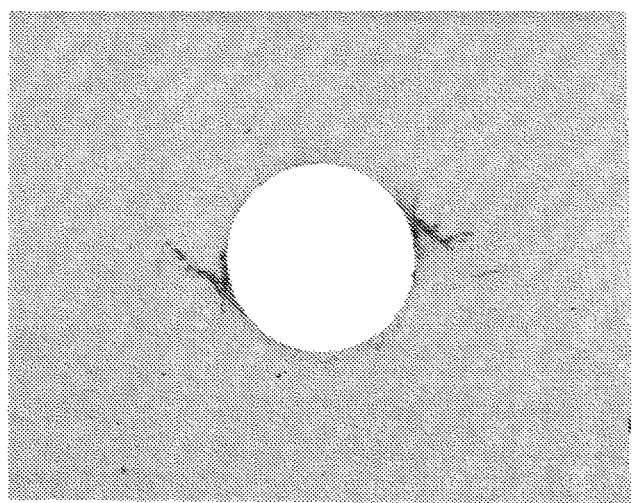

(d) Net-section compression (NC) 


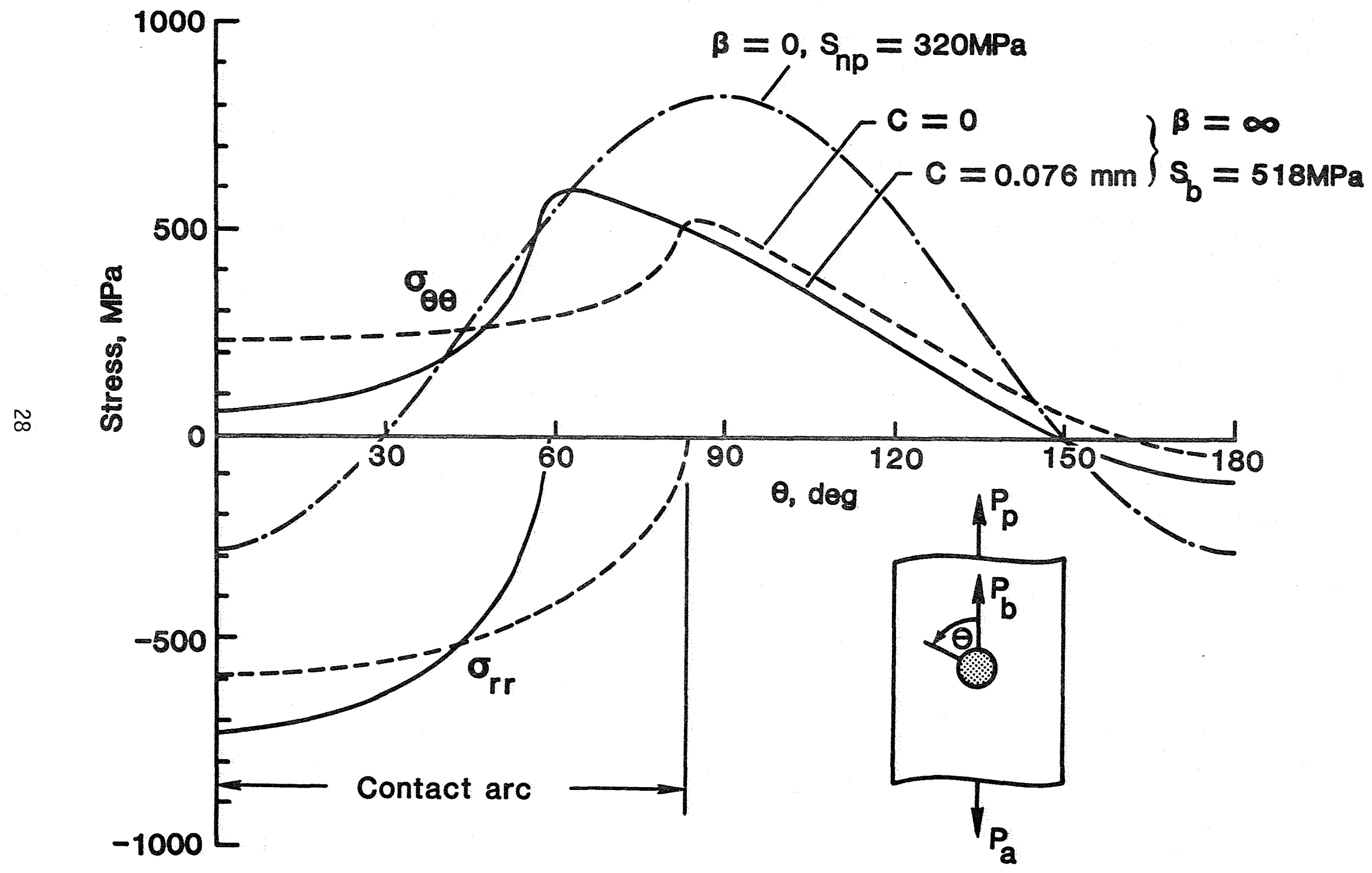

Figure 8. Stresses along hole boundary. 


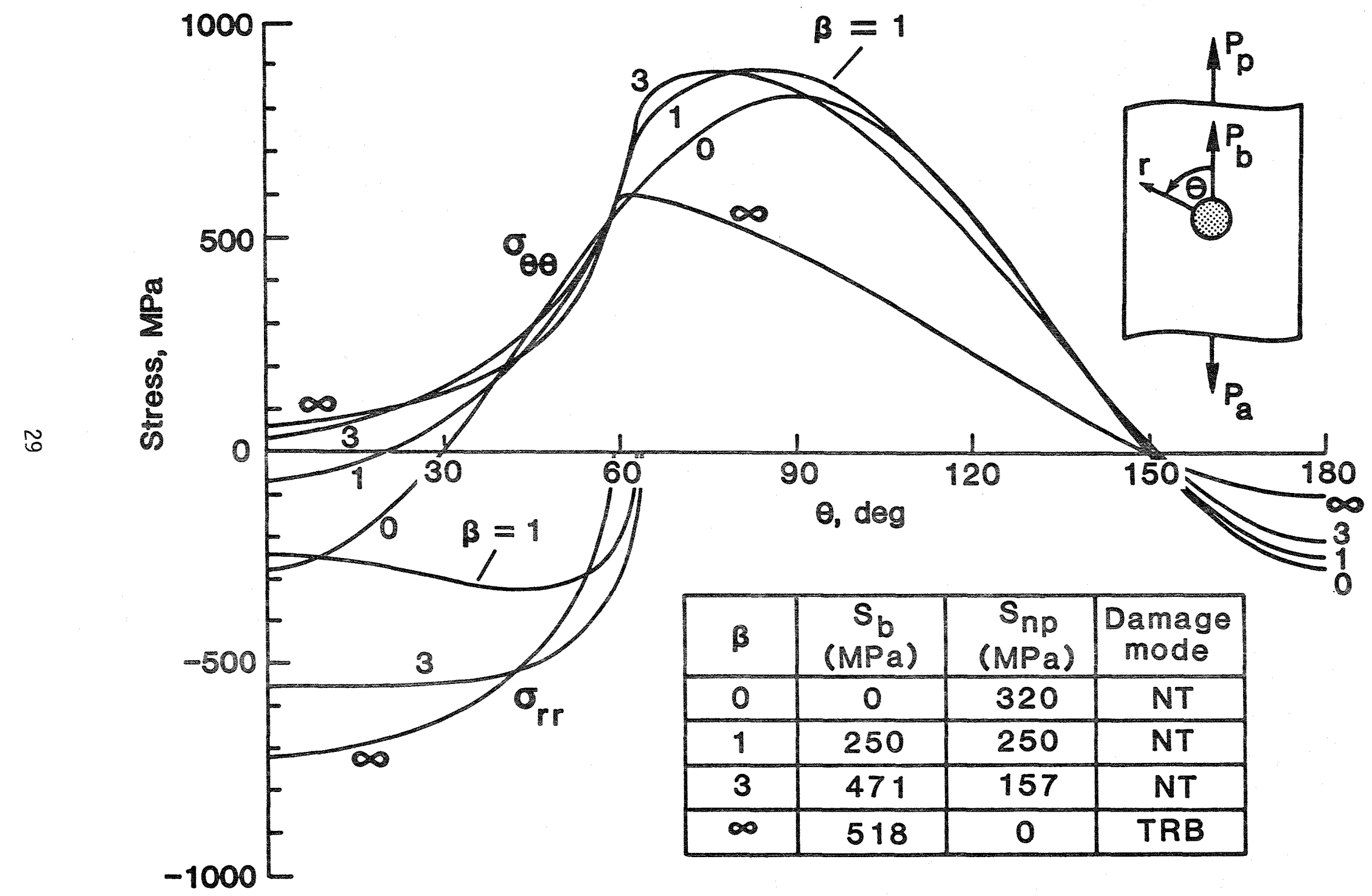

Figure 9. Stresses along hole boundary for tension loading. 


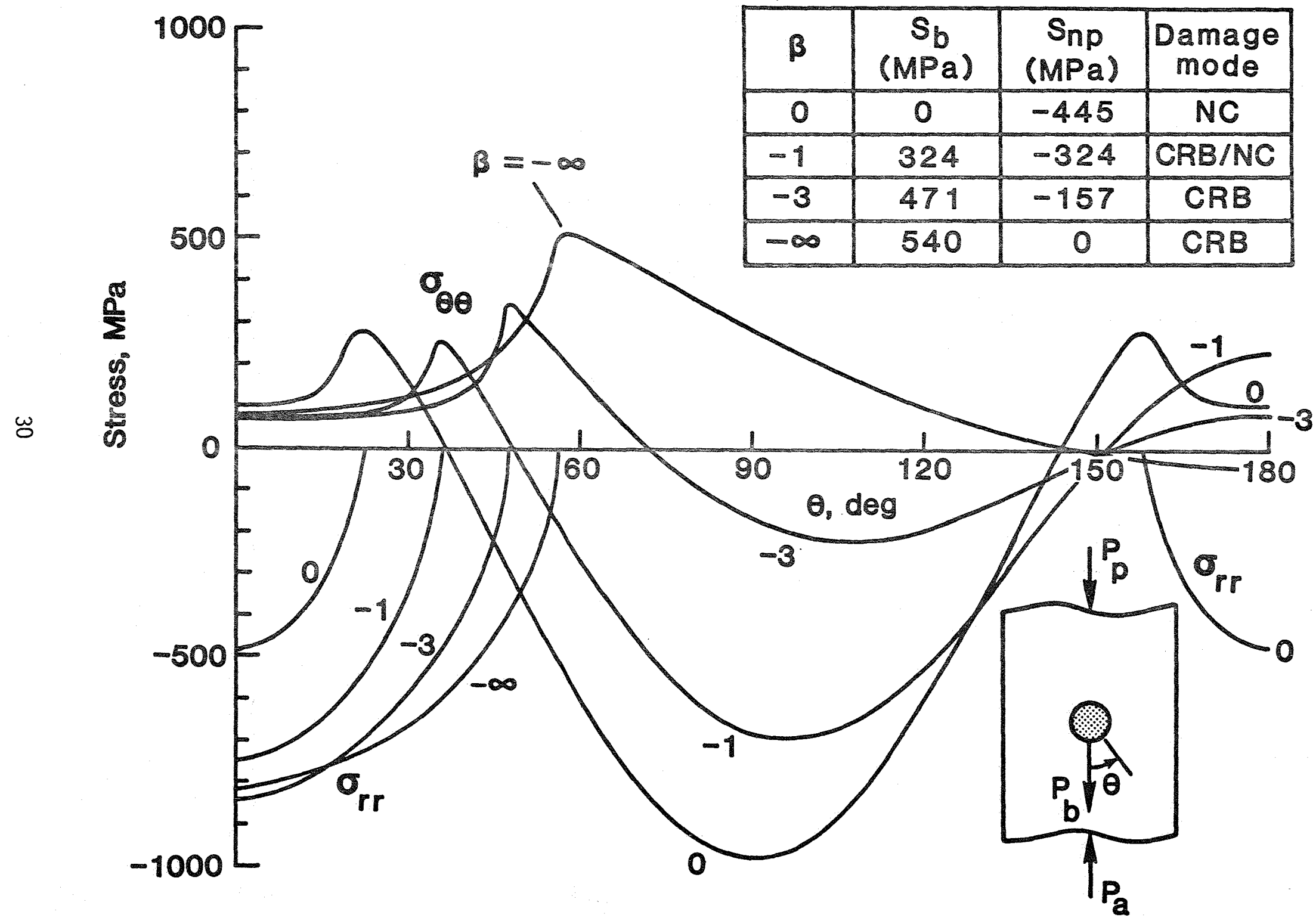

Figure 10. Stresses along hole boundary for compression loading. 


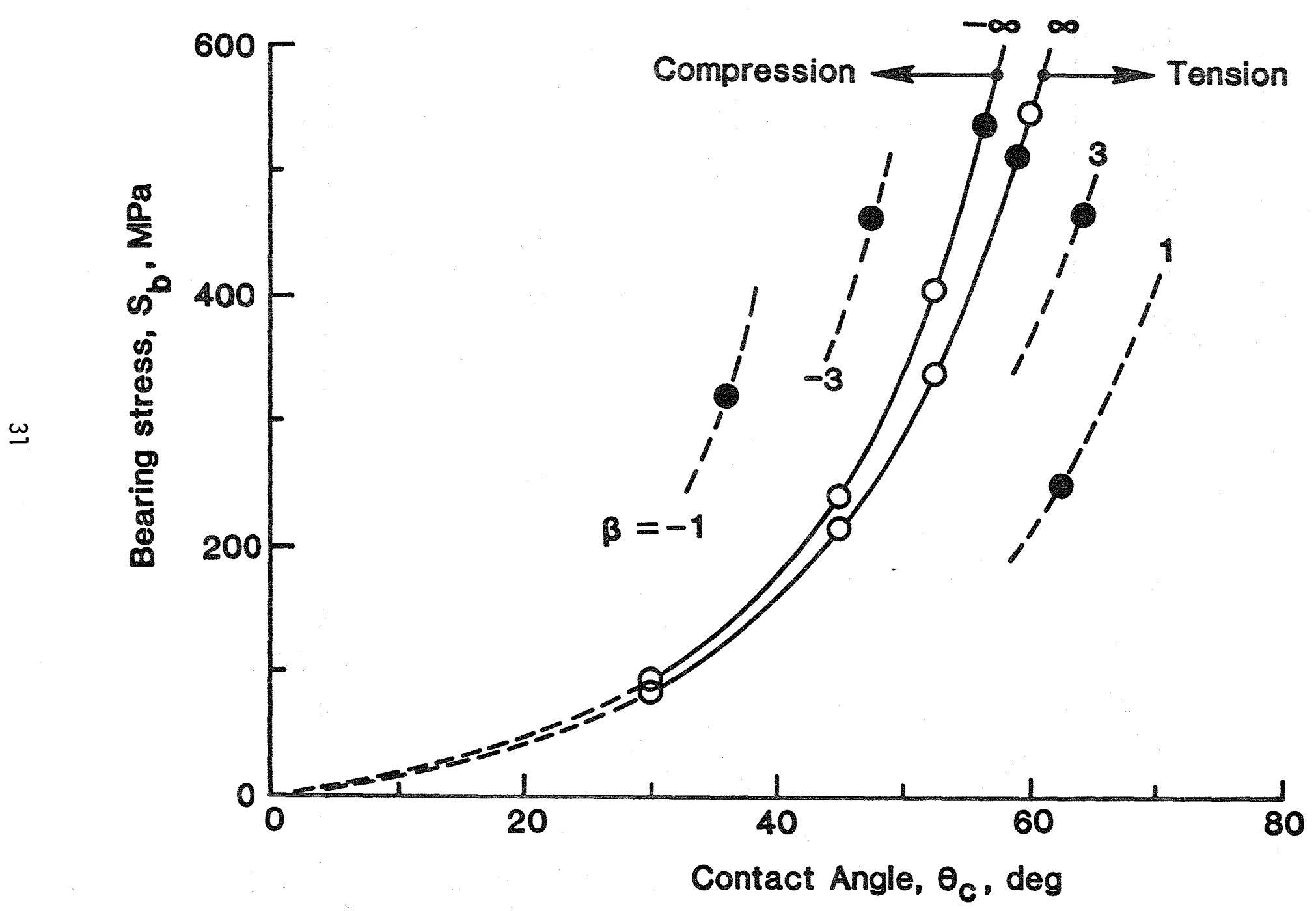

Figure 11. Contact angles for range of bearing stress. 


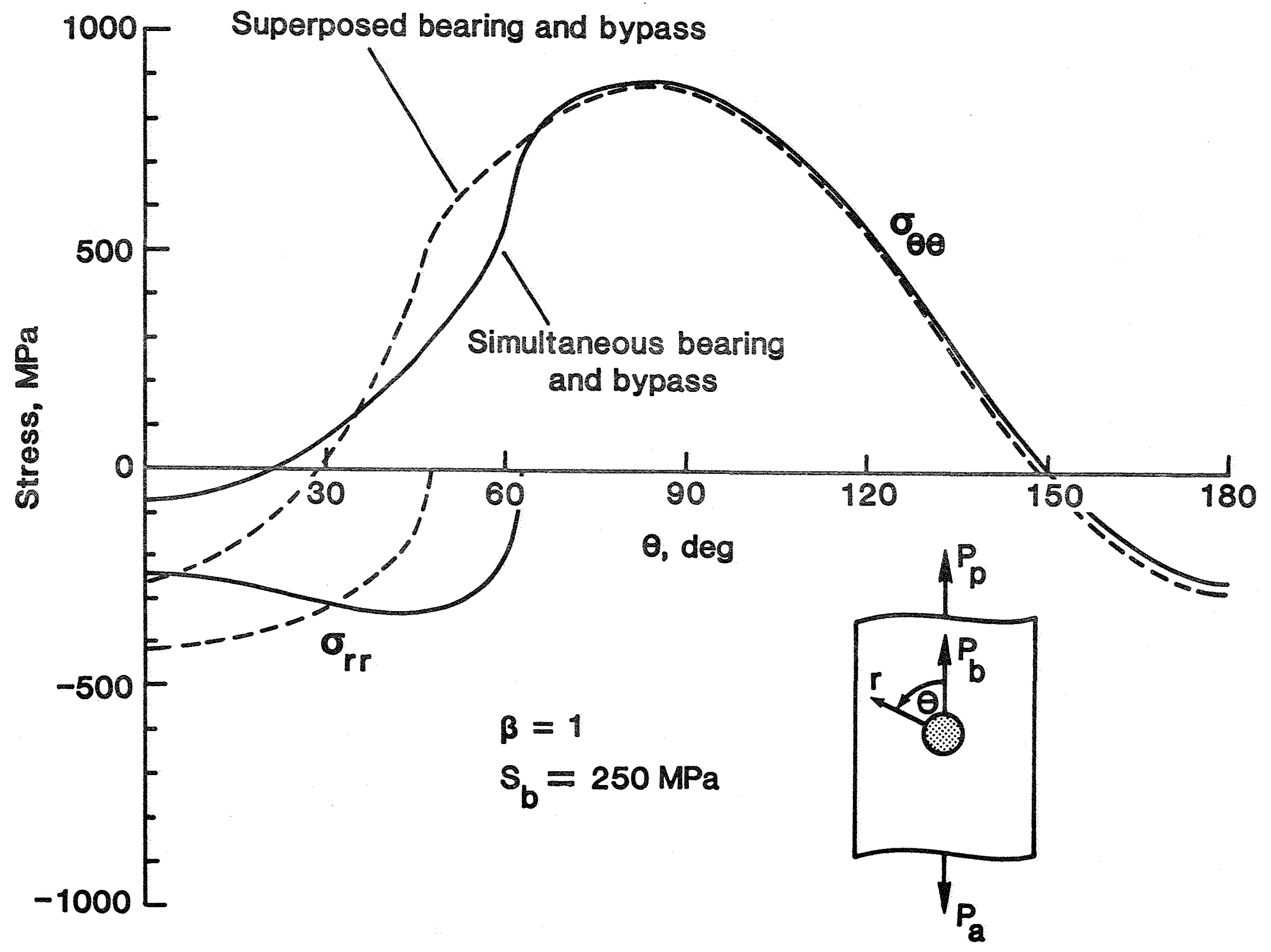

Figure 12. Superposition of hole-boundary stresses for tension loading. 


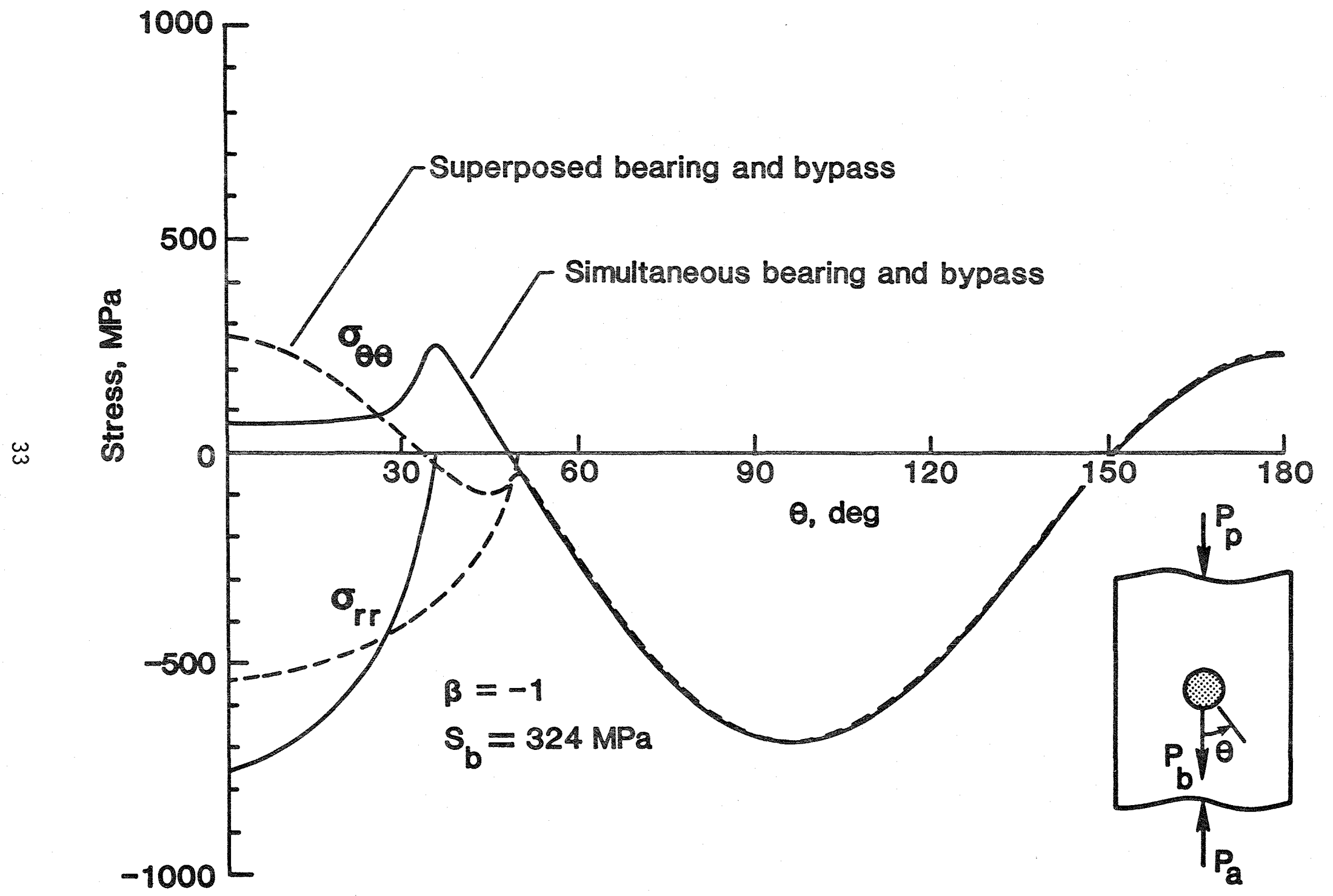

Figure 13. Superposition of hole-boundary stresses for compression loading. 


\begin{tabular}{|c|c|c|c|}
\hline $\begin{array}{l}\text { 1. Report No. } \\
\text { NASA TM-87705 }\end{array}$ & 2. Government Accession No. & \multicolumn{2}{|c|}{ 3. Recipient's Catalog No. } \\
\hline \multirow{2}{*}{\multicolumn{2}{|c|}{$\begin{array}{l}\text { 4. Title and Subtitle } \\
\text { Combined Bearing and Bypass Loading on a } \\
\text { Graphite/Epoxy Laminate }\end{array}$}} & \multicolumn{2}{|l|}{ 5. Report Date } \\
\hline & & \multicolumn{2}{|c|}{ 6. Performing Organization Code } \\
\hline \multicolumn{2}{|l|}{$\begin{array}{l}\text { 7. Author(s) } \\
\text { J. H. Crews, Jr. } \\
\text { R. A. Naik* }\end{array}$} & \multicolumn{2}{|c|}{ 8. Performing Organization Report No. } \\
\hline \multicolumn{2}{|c|}{ 9. Performing Organization Name and Address } & \multicolumn{2}{|l|}{ 10. Work Unit No. } \\
\hline \multicolumn{2}{|c|}{$\begin{array}{l}\text { NASA Langley Research Center } \\
\text { Hampton, VA } 23665-5225\end{array}$} & \multicolumn{2}{|c|}{ 11. Contract or Grant No. } \\
\hline \multirow{2}{*}{\multicolumn{2}{|c|}{$\begin{array}{l}\text { 12. Sponsoring Agency Name and Address } \\
\text { Nationa1 Aeronautics and Space Administration } \\
\text { Washington, DC 20546-0001 }\end{array}$}} & \multicolumn{2}{|c|}{$\begin{array}{l}\text { 13. Type of Report and Period Covered } \\
\text { Technical Memorandum }\end{array}$} \\
\hline & & \multicolumn{2}{|c|}{ 14. Sponsoring Agency Code } \\
\hline \multicolumn{4}{|c|}{$\begin{array}{l}\text { 15. Supplementary Notes } \\
\text { *R. A. Naik, Graduate student, 01d Dominion University, Norfolk, VA } 23508\end{array}$} \\
\hline \multicolumn{4}{|c|}{$\begin{array}{l}\text { 16. Abstract } \\
\text { A combined experimental and analytical study was conducted to determine the } \\
\text { behavior of a graphite/epoxy laminate subjected to combined bearing and bypass } \\
\text { loading. Single-fastener quasi-isotropic specimens were loaded at various bear- } \\
\text { ing-bypass ratios until damage was produced at the fastener hole. Damage-onset } \\
\text { strengths and damage modes were then analyzed using local hole-boundary stresses } \\
\text { calculated by a finite-element analysis. The tension data showed the expected } \\
\text { linear interaction for combined bearing and bypass loading with damage developing } \\
\text { in the net-section tension mode. However, the compression bearing-bypass } \\
\text { strengths showed an unexpected interaction involving the bearing mode. Compress- } \\
\text { ive bypass loads reduced the bearing strength by decreasing the bolt-hole contact } \\
\text { arc and thus increasing the severity of the bearing loads. The bearing stresses } \\
\text { at the hole boundary were not accurately estimated by superposition of the stress } \\
\text { components for separate bearing and bypass loading. However, superposition pro- } \\
\text { duced reasonably accurate estimates for tangential stresses especially near the } \\
\text { specimen net-section. }\end{array}$} \\
\hline $\begin{array}{l}\text { 17. Key Words (Suggested by Authors(s)) } \\
\text { Laminate } \\
\text { Bearing } \\
\text { Bypass } \\
\text { Joint } \\
\text { Stress analysis } \\
\text { Test apparatus }\end{array}$ & $\begin{array}{l}\text { 18. Distribution } \\
\text { Unclass } \mathrm{i} \\
\text { Subject }\end{array}$ & $\begin{array}{l}\text { ment } \\
\text { - Unlimitec } \\
\text { egory } 24\end{array}$ & \\
\hline $\begin{array}{l}\text { 19. Security Classif.(of this report) } \\
\text { Unclass ified }\end{array}$ & $\begin{array}{l}\text { 20. Security Classif.(of this pa } \\
\text { Unc lass ified }\end{array}$ & $\begin{array}{l}\text { 21. No. of Pages } \\
35\end{array}$ & $\begin{array}{l}\text { 22. Price } \\
\text { A03 } \\
\end{array}$ \\
\hline
\end{tabular}


End of Document 